\title{
PSYCHE.
}

\section{NOTES ON THE HABITS OF HYPOTRICHIA SPISSIPES LEC., WITH DESCRIPTION OF THE FEMALES.}

\author{
BY HENRY GUERNSEY HUBBARD, CRESCENT CITY, FLORIDA.
}

Several years ago I found in Florida a male specimen of this beetle, impaled upon a needle of the long-leaved pine (Pinus australis) which had fallen and lay upon the gound with its pointed end projecting upwards. The body was pierced through the back, between the scutellum and the hinge of the elytron. The wing-cases were spread widely open, as in the act of flight. Recently a second male, which is caught in a precisely similar manner, on the end of a broken grass culm, has been sent from Florida to the U. S. Department of agriculture. The beetle is so firmly fastened that the long journey from Florida has not shaken it from the spear of grass.

The repetition of this accident in the case of an insect of such rare occurrence that it.is almost unknown in collections, suggested to me that the beetle might have a mode of flight very different from that of related may-beetles (melolonthidae). This surmise I have been able to verify in a manner that throws some light upon the habits of the beetle.

One day, last spring, during a light shower succeeding a long drought, while standing in an open place I became aware of an insect flying around me with great rapidity, and with a buz- zing noise. Presently I distinguished a beetle which I at first mistook for an abnormally active individual of Euphoria (Cetonia) inda. It flew in circles, close to the earth, and seemed to be in search of something. Finally it made a sudden dart into the loose sand, and almost immediately disappeared beneath the surface. A considerable subterranean commotion, however, marked the spot, and I easily uncovered it at a depth of about five centimetres. It proved to be a male of Hypotrichia spissipes, and as I took in my hand, a second male, with which it had been locked in combat, disengaged itself and flew away. A female, which I fortunately secured, was immediately beneath the struggling males. It would seem, therefore, that Hypotrichia is not entirely crepuscular like its relatives the may-beetles (Lachnosterna), but that it also flies by day; at least in cloudy weather. Its flight resembles that of certain cetonians, which flit, hither and thither, keeping close to the ground. The latter, however, are abroad during the brightest noon-day sunshine. The body, especially in the males, is very thinly chitinized, and this, with its headlong flight, exposes it to such accidents as are recorded above. The females are exceedingly rare. They can 
upon occasion make good use of their wings, but probably fly only at night,

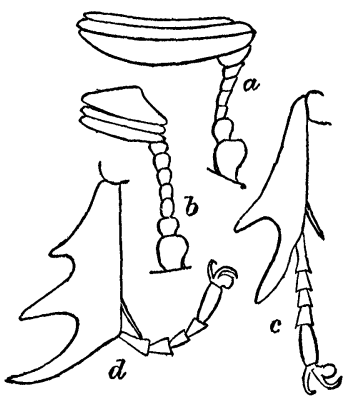

Fig. 13. Hypotrichia spissipes Lec. a, antenna of male; $b$, antenna of female; $c$, front tibia of male; $d$, ditto, female.

and are more subterranean in their habits than the males; this is indicated also by their form, which is heavier, more strongly built, and less pubescent than in the male. As this beetle has hitherto been known in the male sex only, I add a description of the female. ${ }^{1}$

Description of the female.-Color piceo-rufous, head and thorax darker; body shining, beneath sparsely pubescent, above very sparsely covered with short, stifl hairs; head small, convex, eyes small, scarcely visible from above; two basal joints of antennae enlarged, as in the male, the five following joints globular; club equal in length to the five preceding joints, with a conical prominence on its outer face; thorax rounded, convex, coarsely punctate; scutellum short, nearly triangular, not

1 Leconte's original description of the male may be found in his "Classification of the colenptera of North America .... pt. I"'(Smithsonian misc. coll., I862 v. 3), p. 137 . rounded behind ; elytra shining, coarsely but obsoletely punctate, sutural stria well marked; pygidium much wider than long, finely and densely punctate.

The female is somewhat larger, more elongate and more convex than the male and is without the long and dense pubescence so conspicuous in that sex; the head, and especially the eyes are smaller; the thorax is larger, much more convex laterally and longitudinally, the base less lobed at middle, and is much less densely and more coarsely punctured; viewed from above the convexity of the sides conceals the true margin of the thorax which thus appears more regularly rounded than in the male. The five joints which constitute the scape of the antennae are well separated, and not connate as in the male, and the conical projection, which in the male appears upon the edge of the last joint, and gives to the antenna an irregular outline, is centrally placed in the female, and the club is regularly oval in outline.

The legs of the female are stouter, and project rigidly from the body, recalling the characteristic appearance of the oryctini, (Oryctes, Aphonus, etc.). The front legs are especially fossorial, the tibia being very broad, excavate within, and armed with three stout teeth on the outer edge. The male tibia is straighter and narrower, and has only two teeth.

The remarkable sexual differences in this species call to mind the still greater 
dissimilarity of the sexes in Pleocoma, which genus has been placed by Leconte in the distant coprophagous series of Lamellicorns. Quite recently Gerstäcker has pointed out ${ }^{2}$ the close relationship which exists between Pleocoma and the European genus Pachypus, the latter an undoubted melolonthian. The females in these genera resemble each other closely, and in both are without wings or wingcovers.

It seems probable that Leconte was somewhat misled by the determination of a larva described by Osten Sacken as that of Pleocoma. ${ }^{3}$ This larva is supposed by Gerstäcker to belong to a lucanid beetle, but it may with greater probability be conjectured to be the larva of a Gieotrupes.

Between the females of Hypotrichia and those of Pleocoma evidences of relationship are not wanting, and as both must now be considered members of the melolonthian series, a closer comparison than has yet been made will possibly bring the two genera into still more intimate relations. The series of genera, Hypotrichia, Plectrodes and Pleocoma, exhibits a very instructive passage from a winged insect with active powers of flight, as in the male of Hypotrichia, to the degraded, wingless, and wholly subterranean female of Pleocoma.

\footnotetext{
2 Entom zeit .... Stettin, I883, jahrg. 44, p. 436.
}

3 Trans. amer. entom. soc., 1874, v. 5, p. 84 .
Drinking Habit of a Moth. ${ }^{1-}$ E. D. Jones describes a remarkable drinking habit of a yellow and black Brazilian moth (Panthera [corr.] pardalaria). He found these moths sitting on the wet stones in small streams near San Paulo, sucking up the water in a continuous stream, and letting it escape in drops from the abdomen. These drops fell at the average rate of 50 per minute, and as near as he could judge of their size, the total quantity of water which must thus pass through the body of the moth in three hours must be a cubic inch, or about 200 times the bulk of its own body. Mr. Jones speculates on the possible meaning of this

1 Proc. lit. and phil. soc. Liverpool, 1883, v. 37, p. $76-77$. and asks-"Can it be that the moth extracts nourishment from minute particles of organic matter contained in the water?" $\mathrm{He}$ remarks, however, that the water of the streams appear very clear and pure, and notes that the moths seems specially adapted for this habit. The tibiae of the hind legs are very thick, and are armed with long hairs, which by their capillary action prevent the moth being immersed in the water. "I have often," he adds, "seen one of them knocked down by a little spurt of water splashing over the stone on which it was standing, and it recovered itself almost immediately without being wetted in the least."-Fourn. roy. micros. soc., Oct. 1884, s. 2, v. 4, p. 74I. 

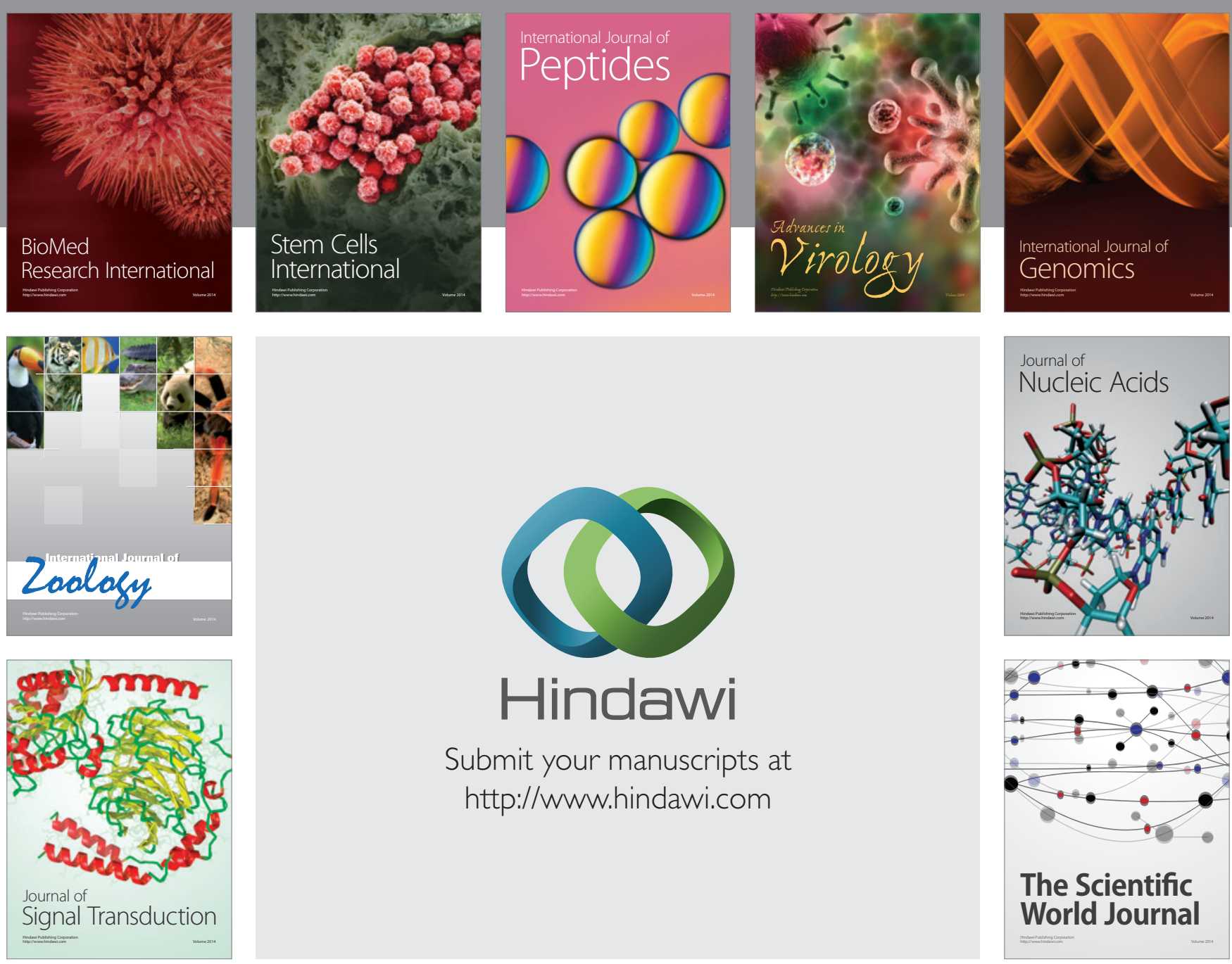

Submit your manuscripts at

http://www.hindawi.com
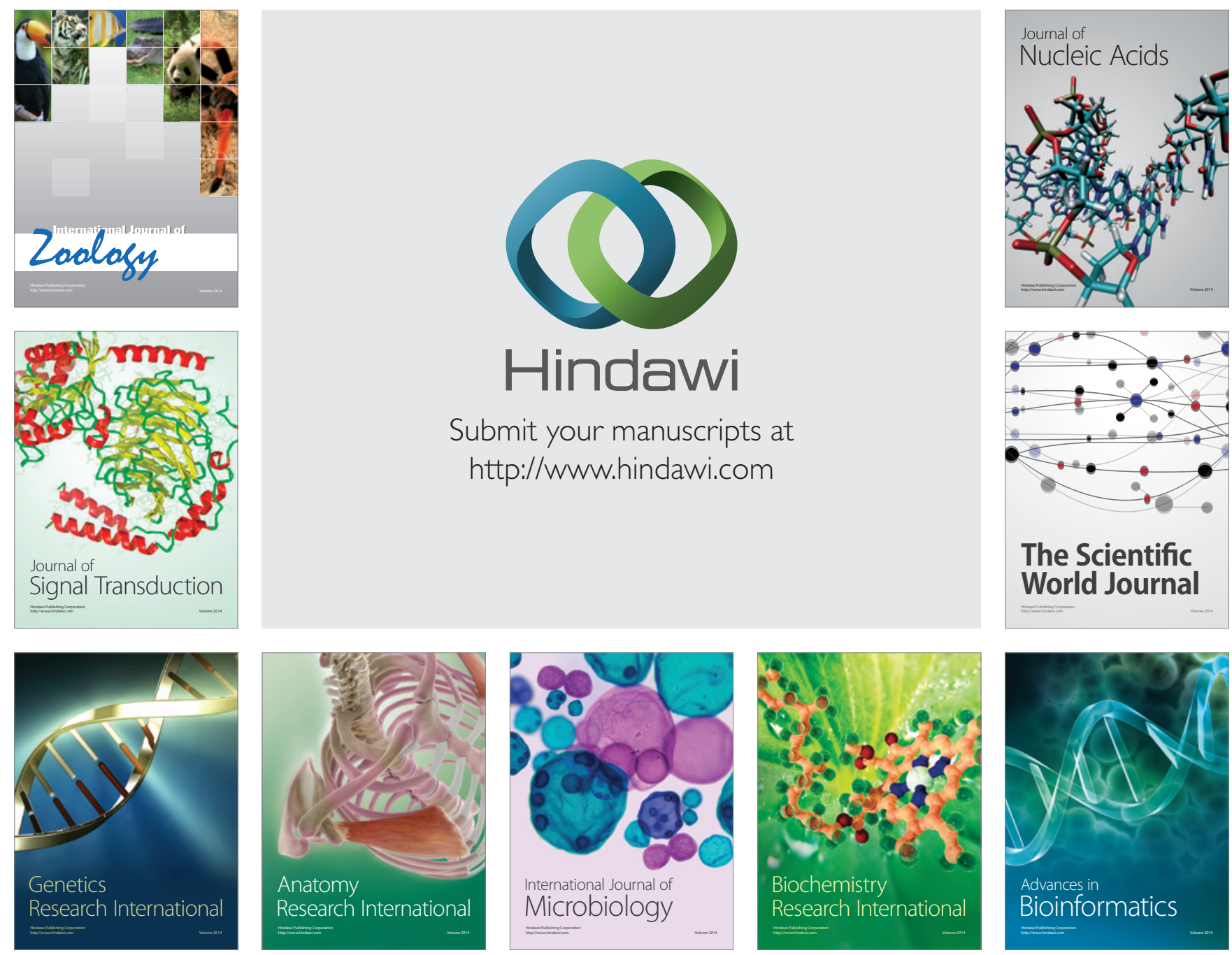

The Scientific World Journal
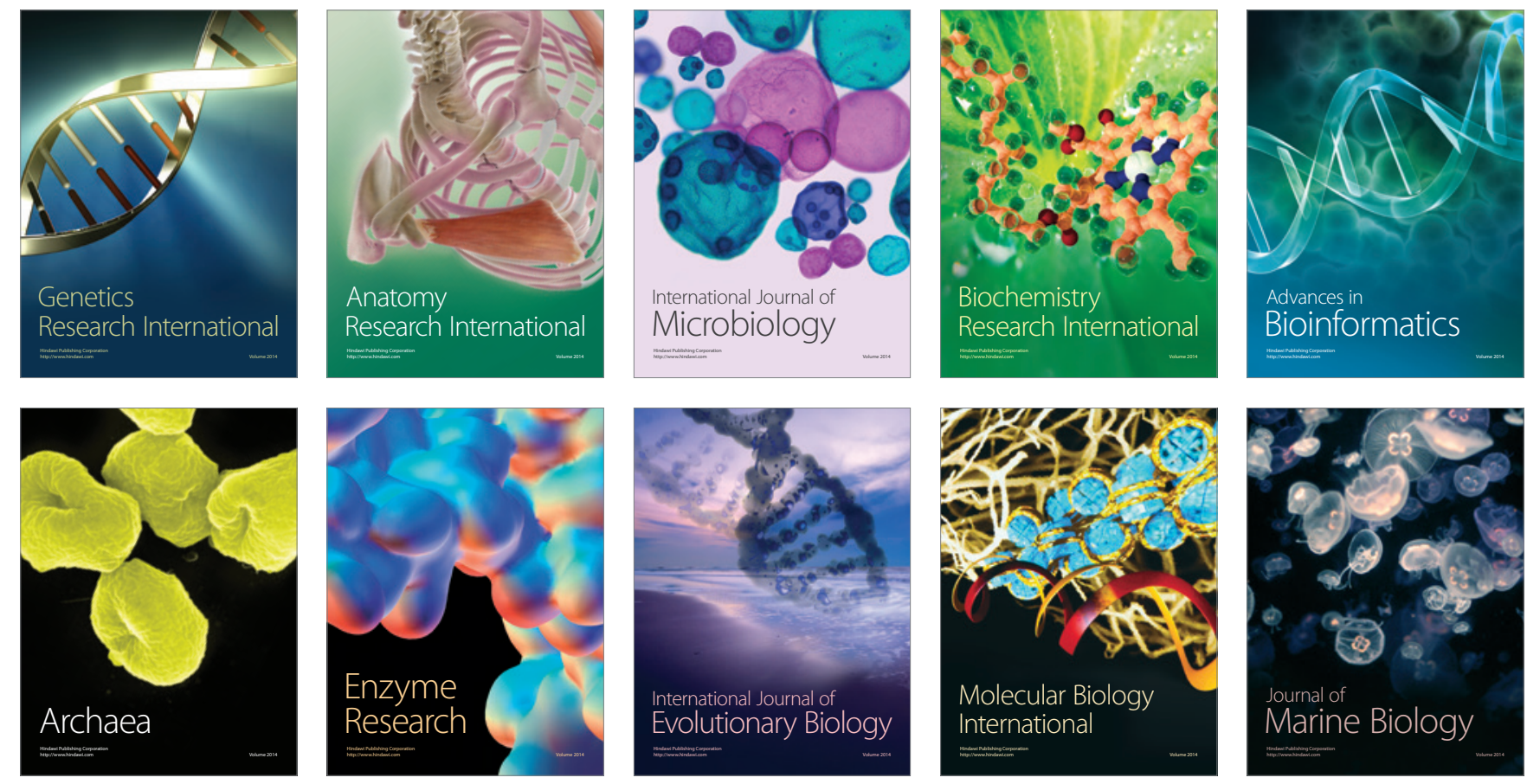